\title{
The Effect of Inclination Angle and Reynolds Number on the Performance of a Direct Contact Membrane Distillation (DCMD) Process
}

\author{
Adnan Alhathal Alanezi ${ }^{1}$ (D), Mohammad Reza Safaei ${ }^{2,3,4, *(D)}$, Marjan Goodarzi ${ }^{5}$ and \\ Yasser Elhenawy ${ }^{6}$ (D)
}

1 Department of Chemical Engineering Technology, College of Technological Studies, The Public Authority for Applied Education and Training (PAAET), P.O. Box 42325, Shuwaikh 70654, Kuwait;

aa.alanezi@paaet.edu.kw

2 Institute of Research and Development, Duy Tan University, Da Nang 550000, Vietnam

3 Faculty of Electrical-Electronic Engineering, Duy Tan University, Da Nang 550000, Vietnam

4 Center of Research Excellence in Renewable Energy and Power Systems, King Abdulaziz University, Jeddah 21589, Saudi Arabia

5 Sustainable Management of Natural Resources and Environment Research Group, Faculty of Environment and Labour Safety, Ton Duc Thang University, Ho Chi Minh City 700000, Vietnam;

marjan.goodarzi@tdtu.edu.vn

6 Mechanical Power Engineering Department, Port-Said University, Port Fuad 42526, Egypt;

dr_yasser@eng.psu.edu.eg

* Correspondence: mohammadrezasafaei@duytan.edu.vn; Tel.: +1-502-657-9981

Received: 10 April 2020; Accepted: 23 May 2020; Published: 2 June 2020

check for updates

\begin{abstract}
In this numerical study, a direct contact membrane distillation (DCMD) system has been modeled considering various angles for the membrane unit and the Reynolds number range of 500 to 2000. A two-dimensional model developed based on the Navier-Stokes, energy, and species transport equations were used. The governing equations were solved using the finite volume method (FVM). The results showed that with an increase in the Reynolds number of up to 1500, the heat transfer coefficient for all membrane angles increases, except for the inclination angle of $60^{\circ}$. Also, an increase in the membrane angle up to $90^{\circ}$ causes the exit influence to diminish and the heat transfer to be augmented. Such findings revealed that the membrane inclination angle of $90^{\circ}$ (referred to as the vertical membrane) with Reynolds number 2000 could potentially have the lowest temperature difference. Likewise, within the Reynolds numbers of 1000 and 2000, by changing the inclination angle of the membrane, temperature difference remains constant, however, for Reynolds numbers up to 500 , the temperature difference reduces intensively.
\end{abstract}

Keywords: direct contact membrane distillation; membrane inclination angle; heat and mass transfer; Reynolds number

\section{Introduction}

The membrane distillation (MD) process is one of the emerging operating processes for physical and chemical separation. A non-isothermal process is used in an MD process to separate a specific impurity from a medium, in which water is the constituent [1-4]. The separation process in an MD unit is based on the vapor-liquid equilibrium, where vapor passes from the irregularities, and pores of the hydrophobic layer of the membrane [5,6]. The MD process offers an efficient and reliable water purification, since it employs a hydrophobic microporous membrane. Importantly, the transmembrane temperature gradient in an MD process provides a driving force for transferring the water vapor 
through the hydrophobic membrane $[7,8]$. In a desalination process, the low operating temperature and pressure of MD are favorable and are advantageous in comparison with energy-intensive processes, which improves the economic viability of the process. Thereby, utilizing a renewable and affordable source of energy, such as solar energy, can add another advantage to the MD process [9-11]. Separation is considered a prohibitive physical stage in chemical plants. Hence, MD process is attracting particular interest compared to the conventional separation processes, such as reverse osmosis (RO), multi-stage flash distillation (MSF), adsorption, absorption, and extraction, primarily due to the following reasons [12-17]:

(1) The operating temperature and pressure are lower than the conventional processes.

(2) The ability to produce high-quality pure water.

(3) The renewable energy can be used as a source of energy for driving the process.

(4) The operation, and utilization, of the solvents is simple.

(5) It is a compact process with scalability and economic viability.

(6) It has the ability for rejections, colloids, and other non-volatile components, at a rate of 100 percent.

(7) It is fully automated, and it does not have any moving configuration compared to the MSF process.

One of the main causes of low water flux in the MD is severe temperature-polarization, which is attributed to poor fluid dynamics, where it leads to decrease the driving force across the hydrophobic membrane $[6,18,19]$. The water vapor mass transfer through the membrane pores is enhanced by the vapor pressure difference, as well as the temperature difference that exists between the feed and permeates sides of the hydrophobic membrane, as shown in Figure 1 [8,20,21]. In the last decades, comprehensive investigations have been performed concerning the effects of various operating parameters on the permeate flux of the MD process $[15,18,22]$. However, there have been no breakthroughs in several aspects, such as a novel MD module design [1,5]. Additionally, less progress has also been made in the efforts towards the prediction of permeate flux, membrane fouling, the effect of polarization, and the percentage of solute rejection as a function of operating conditions and time. The other concern in the MD industrialization is sustainable, suitable, and trustable heat resources $[1,23]$.

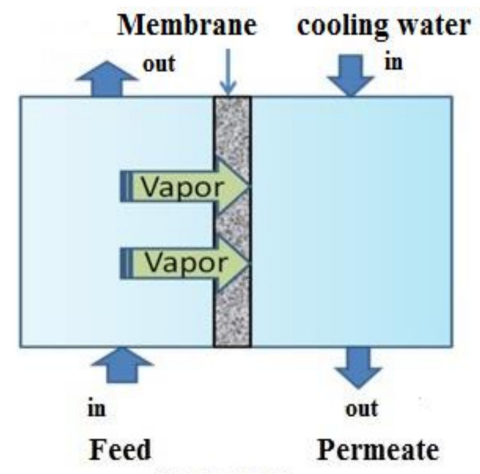

(a) DCMD

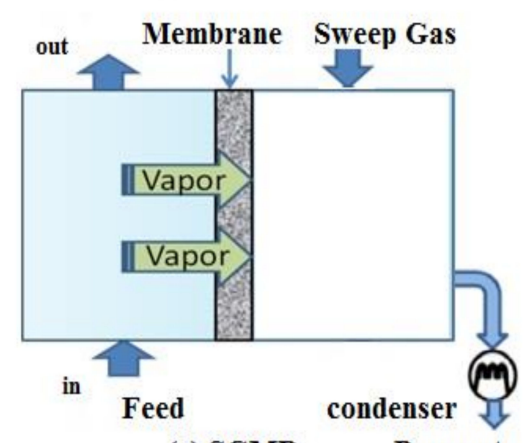

(c) SGMD

Permeate

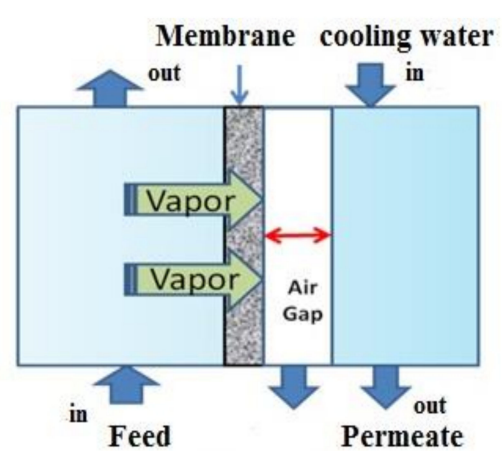

(b) AGMD

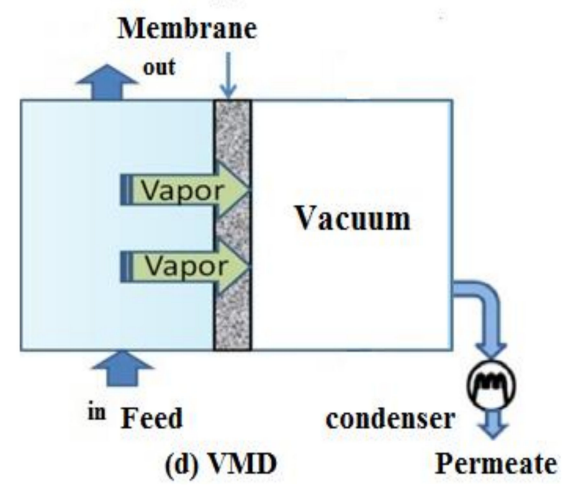

Figure 1. Schematic illustrations of the membrane distillation (MD) configurations [20]. 
Based on the permeation procedure of the condensed vapor to the membrane, MD is categorized into four different configurations, as shown in Figure 1, including (a) direct contact membrane distillation (DCMD), (b) vacuum MD (VMD), (c) air gap MD (AGMD), and (d) sweeping gas MD (SGMD) $[15,20,24,25]$. Amongst the four configurations, the DCMD has been more attractive due to the high permeate flux $[15,25,26]$. The DCMD process is applied in water desalination [18], wastewater treatment of the textile contaminated with color [27], wastewater treatment from rubber wastewater [28], treatment contaminated with radioactive and heavy metal [29], and wastewater treatments, such as food processing [30] and dairy product concentration [31].

For a proper understating of the combination of mass and heat transfer in the MD process, there is a need for a full description of the temperature distribution adjacent to the membrane along the module length, where the mass and heat fluxes are mainly influenced by the boundaries' layers of feed and permeate across the hydrophobic membrane. The calculations of the heat transfer coefficient at the boundary layer in MD process are based on empirical correlations that are available in the literature. It is, however, difficult to select a suitable Nusselt number correlation that represents the heat transfer in MD process precisely [32]. In recent years, the use of a miniature sensor has been applied in the effort to measure the interfacial temperature; however, the miniature sensor has its disadvantages, such as the sensor interfering with the thermal boundary layers [33]. Another novel method of using thermochromic liquid crystal has been performed to measure temperatures inside the MD module [34,35].

Recently, various mathematical models have been proposed to predict the performance of the MD process $[23,36]$. In addition to modeling, computational fluid dynamics (CFD) is widely used to evaluate the behavior and the fluid dynamic in MD separation modules. Therefore, the CFD solver offers some great features which can be implemented in developing a new insight on the effect of different operating parameters on the MD performance, such as understanding the effect of the temperature and concentration polarization, which can be useful before performing costly experiments $[23,37,38]$. The approach of computational fluid dynamics (CFD) for surveying the heat and mass transfer in DCMD process is performed due to the same effect of each phenomenon [39,40]. Much effort has been made to employ CFD in solving DCMD related studies. For example, Janajreh and Suwwan [41] modeled a DCMD process of hydrophobic membrane polyvinylidene fluoride (PVDF) membrane using Navies-Stokes equations. They analyzed heat flux, mass flux, temperature polarization, and thermal efficiency by changing the flow conditions and membrane conductivity. The results indicated that mass flux increases by increasing the inlet flow. They also found that the membrane with lower conductivity creates more temperature differences, which in turn leads to an increase in the heat and mass fluxes. N. Tang et al. [42] studied the heat and mass transfer of VMD process as a liquid and gas phase in porous media using the CFD technique. The experiment involved a hollow fiber module equipped with PVDF membrane for desalination and purposes via the VMD process. Modeling of the heat and mass transfer was conducted two-dimensionally. The heat and mass of the evaporation process were conducted through the mixture model, porous media condition, standard k- $\varepsilon$ model, and the user-defined function of evaporation. The authors' focus on the experiment was to model the effect of feed temperature and flow rate on the VMD distillate flux. The result observed indicated that the increase in feed temperature caused an increase in the volume fraction of produced water vapor. Shakaib et al. [37]'s works provide a study of the effects of the hydrodynamic condition in the DCMD; for example, inlet velocity, temperature polarization, and spacer orientation. The investigation was conducted by the CFD simulation, which observed that spacer orientation affects the temperature polarization and rates of heat transfer.

Awad et al. [43] modeled a DCMD process by using the conjugate energy equation/Navier-Stokes model. In this investigation, steady-state, two-dimensional, and counter, as well as parallel flows, were considered. At the same time, the permeate and feed temperature were $25^{\circ} \mathrm{C}$ and $40{ }^{\circ} \mathrm{C}$, respectively. The results showed that an increase in the temperature difference for counter and parallel flow models could cause the mass flux to promote. They also found that the counter-flow evinces a 
higher mass flux compared to parallel flow. Janajreh et al. [44] developed a model to quantitatively distinguish between the DCMD and the point of porosity view. The model included the non-isothermal Navier-Stokes equations, coupled with porous membrane thermal modulization. Inlet temperature was constant at $75^{\circ} \mathrm{C}$, whereas composites of the membrane structure and its porosity were changed during the simulations. The results showed that an increase in porosity causes an enhancement of $11 \%$ in MF. In comparison, the porosity reduction leads to a $22 \%-25 \%$ decrement. Chen et al. [45] numerically modeled the DCMD process to estimate its temperature polarization coefficient (TPC). Poiseuille and Knudsen flow model was considered in the model through a laminar flow assumption. For the verification, they tailored their model to a DCMD based flat plate. The results of modeling showed that with an increase in the brine temperature, the permeate flux in the pure water side was enhanced. The same result was achieved for the flow rate as well. Bahmanyar et al. [46] conducted a simulation to investigate the effect of the feed characteristics, including, but not limited to, inlet concentration, temperature, and circulation rate on the permeate flux. The results showed that the feed temperature has more efficacies on TPC in comparison to the inlet concentration. Janajreh et al. [47] carried out experiments on the effects of a conductive layer and geometry undulation on the DCMD efficiency. The measured surface temperature distribution and TPC represented a reasonably good agreement with those obtained with the model.

Faced with the above literature, it can be stated that the MD is a low energy process [48] with reasonable economic viability, and the purity of the product is also acceptable. Despite extensive research conducted on the influence of different operating parameters, to the best of our knowledge, there is a shortcoming in the understanding of the effect of the membrane angle inclination and Reynolds number. Hence, in the present work, the performance of the direct contact membrane distillation at various inclination angles and Reynolds numbers were numerically analyzed. A two-dimensional model was developed to achieve the optimum angle of the DCMD process between 0 and $90^{\circ}$. The results were deeply discussed, and the optimum operating conditions were introduced. The obtained results illustrated that changing the membrane angle can save energy for purification phenomenon.

\section{Problem Statement}

Figure 2 shows the schematic illustration of the modeled DCMD with the inclination angle $(\theta)$. The top side of the MD includes a hot feed channel, and a cold permeate fluid flows through the bottom channel of the membrane. The total length of configuration is $250 \mathrm{~mm}$, the depth of the hot channel is similar to cold channel equal $3 \mathrm{~mm}$, and the membrane thickness is $0.5 \mathrm{~mm}$. Pure water molecules evaporate at the feed side of the membrane and cross the membrane body, condensing at the permeate side. Based on the previous findings, the membrane characteristics, temperature of the hot and cold sides, and the system pressure can potentially determine the DCMD efficiency [49].

Following the earlier study [50], membrane characteristics, vapor, and PVDF properties are selected and represented in the following Table 1.

Table 1. Physical and thermal and properties of the membrane modeled in the present study taken from the literature [50].

\begin{tabular}{|c|c|c|c|c|}
\hline Material & $\begin{array}{l}\text { Density } \\
\left(\mathrm{kg} / \mathrm{m}^{3}\right)\end{array}$ & $\begin{array}{l}\text { Heat Capacity } \\
\text { (J/kg K) }\end{array}$ & $\begin{array}{l}\text { Thermal Conductivity } \\
(\mathrm{W} / \mathrm{m} \mathrm{K})\end{array}$ & $\begin{array}{l}\text { Viscosity } \\
\text { (pas) }\end{array}$ \\
\hline Polyvinylidene fluoride (PVDF) & 1175 & 1325 & 0.2622 & - \\
\hline Vapor & 0.554 & 2014 & 0.0261 & - \\
\hline Membrane & 302.2 & 1896.9 & 0.0662 & - \\
\hline Saline sea water & 1013.2 & 4064.8 & 0.642 & $5.86 \times 10^{-4}$ \\
\hline Pure water & 995.2 & 4182.1 & 0.613 & $8.38 \times 10^{-4}$ \\
\hline
\end{tabular}




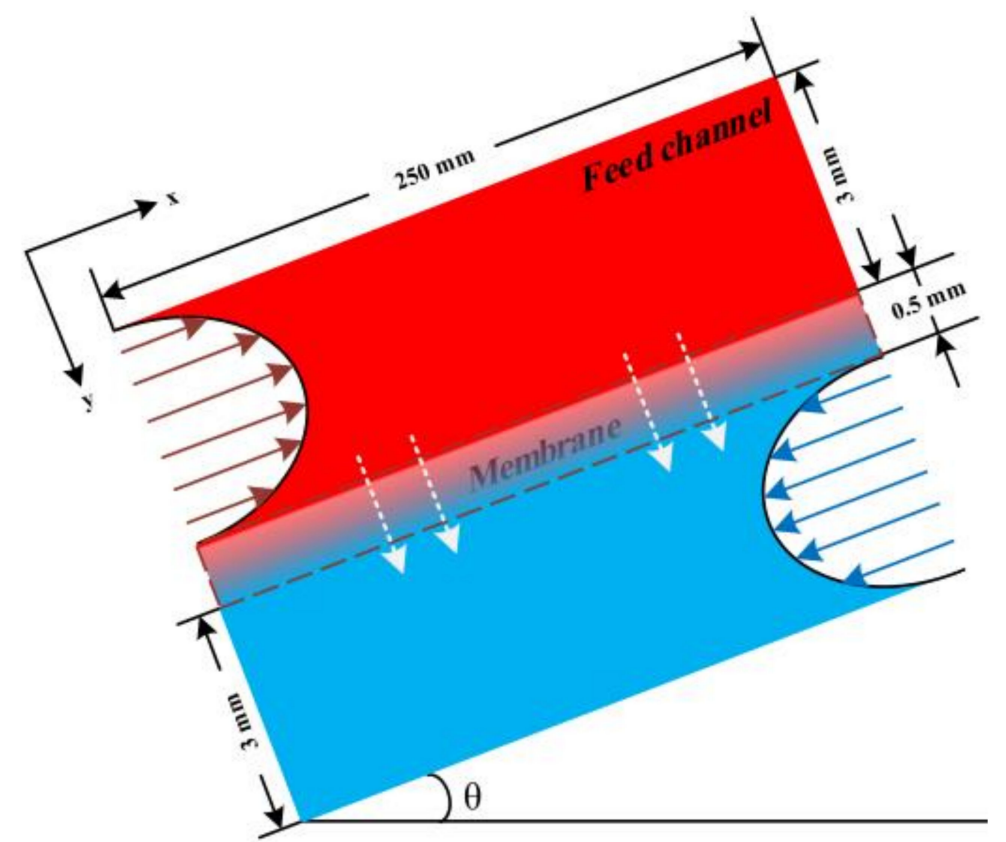

Figure 2. An illustration of the modeled direct contact membrane distillation (DCMD) unit and its geometrical specifications.

\section{Governing Equations and Assumptions}

A two-dimensional model was developed in a Cartesian coordinate system. The flow is steady-state, fully-developed, incompressible, and non-isothermal for both fluid flow of channels. The occurred momentum in the permeate side into the membrane has a scarce effect on the results, so it has been relinquished from the calculations. Walls have no-slip condition, and the insulation condition is placed on the outer wall, so no heat loss has occurred. Compared to the membrane segment, the side of the membrane has no penetration. Due to the low content of $\mathrm{NaCl}$ solid in water $(1 \%)$, polarization has no sensible influence, so it has been ignored. The Knudsen and Poiseuille flow model is also utilized in the transmembrane mass flow calculations $[47,51]$. The Navier-Stokes equations and energy equation were used to define the flow, together with the heat transfer in the membrane system, as follows [52]:

$$
\frac{\partial \rho U}{\partial x}+\frac{\partial \rho V}{\partial y}=0
$$

$\mathrm{x}$-Momentum is

$$
U \frac{\partial \rho U}{\partial x}+V \frac{\partial \rho U}{\partial y}=-\frac{\partial P}{\partial x}+\mu\left(\frac{\partial^{2} U}{\partial x^{2}}+\frac{\partial^{2} U}{\partial y^{2}}\right)+\rho \beta g\left(T-T_{0}\right) \sin \theta
$$

y-Momentum is

$$
U \frac{\partial \rho U}{\partial x}+V \frac{\partial \rho U}{\partial y}=-\frac{\partial P}{\partial y}+\mu\left(\frac{\partial^{2} V}{\partial x^{2}}+\frac{\partial^{2} V}{\partial y^{2}}\right)+\rho g \beta\left(T-T_{0}\right) \cos \theta
$$

Energy equation is

$$
U \frac{\partial \rho C_{P} T}{\partial x}+V \frac{\partial \rho C_{P} T}{\partial y}=k\left(\frac{\partial^{2} T}{\partial x^{2}}+\frac{\partial^{2} T}{\partial y^{2}}\right)+S_{h}
$$

where $\mu, \rho, V, U$, and $P$ are viscosity, density, velocity in the $y$-direction, velocity in $x$-direction, and pressure, respectively. Likewise, in the energy equation, specific heat, temperature, and thermal 
conductivity are defined as $C_{P}, T$, and $k$, respectively. $S_{h}$ is a source term of energy transport which is defined as follows:

$$
\begin{array}{cl}
S_{h}=\frac{Q_{L a}}{\delta y} \times \frac{y_{m o}}{y_{m i}} & ; \mathrm{y}=y_{m i} \\
S_{h}=-\frac{Q_{L a}}{\delta y} & ; \mathrm{y}=y_{m o} \\
0 & ; \text { otherwise }
\end{array}
$$

where $Q_{L a}$ is transmembrane latent heat flux at the hot side membrane surface, and $y_{m o}$ and $y_{m i}$ are distance at $y$-direction of the inner and outer layer of membrane, respectively. $\delta_{y}$ signifies the grid quantity in the $y$-direction.

Feed flow is a multi-component flow, hence the equation for describing the transport of species with concentration $C$ and diffusion coefficient $D$ as follows [53]:

$$
U \frac{\partial C}{\partial x}+V \frac{\partial C}{\partial y}=D\left(\frac{\partial^{2} C}{\partial x^{2}}+\frac{\partial^{2} C}{\partial y^{2}}\right)
$$

\section{Modeling Approach}

The governing equations were solved using the finite volume method (FVM), an approach that is a particular case of the residual weighting scheme [54]. The method is based on the division of the main domain into finite control volumes. Hence, each control volume is named by an individual node. Each finite volume element, the above equations are solved [55]. On the other hand, the terms discretization was performed by adopting a second-order upwind [56]. Likewise, the velocity and the pressure definitions were coupled together using the SIMPLE algorithm [57]. Once the residuals were less than $10^{-6}$, the calculation was stopped [58].

\subsection{Grid-Independent Study}

Due to the importance of the temperature and the velocity profile near the walls of the membrane, the grids were carefully refined at those places using the inflation layer. A grid independence study was performed by testing various distributions of the grids. For this purpose, the heat transfer coefficient (HTC) of several grids was calculated and are enlisted in Table 2, and the trend of the change is depicted in Figure 3. According to the figure, meshing with 420,000 grids showed the optimum results and, therefore, they were considered as the selected mesh for all cases.

Table 2. Grid independence study conducted for the developed model in the present study.

\begin{tabular}{ccc}
\hline Number of Meshes & Position & $\mathbf{h}\left(\mathbf{W} / \mathbf{m}^{\mathbf{2}} \mathbf{K}\right)$ \\
\hline \multirow{2}{*}{262,500} & Bottom & 1035.2397 \\
\cline { 2 - 3 } & Top & 1052.0011 \\
\hline \multirow{2}{*}{350,000} & Bottom & 999.0980 \\
\cline { 2 - 3 } & Top & 980.1226 \\
\hline \multirow{2}{*}{420,000} & Bottom & 1032.7790 \\
\cline { 2 - 3 } & Top & 1049.6522 \\
\hline \multirow{2}{*}{525,000} & Bottom & 1031.4225 \\
\cline { 2 - 3 } & Top & 1048.5602 \\
\hline \multirow{2}{*}{700,000} & Bottom & 1031.0755 \\
\cline { 2 - 3 } & Top & 1048.1479 \\
\hline \multirow{2}{*}{960,000} & Bottom & 1030.9573 \\
\hline & Top & 1048.0280 \\
\hline
\end{tabular}




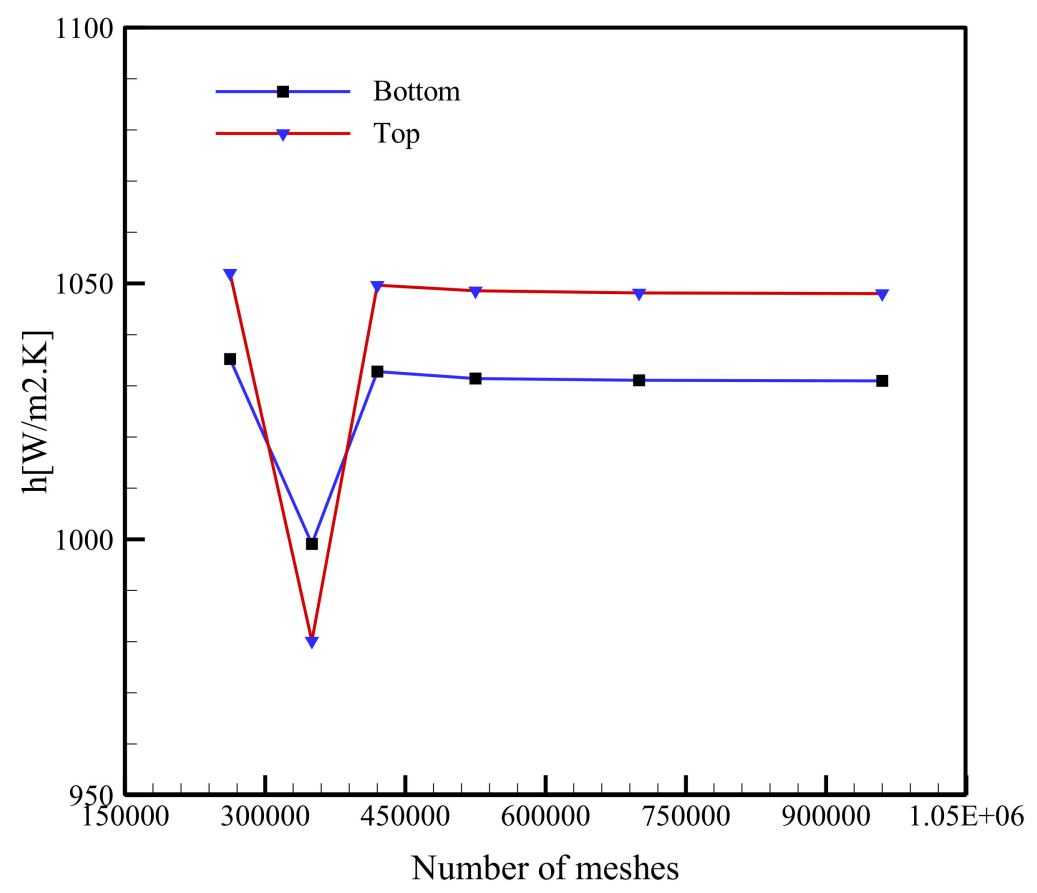

Figure 3. The heat transfer coefficient (HTC) value calculated at different mesh numbers.

\subsection{Validation}

To validate the model, the obtained results were compared to those reported by Janajreh et al. [50] as shown in Table 3, where AGMD and DCMD were numerically analyzed to evaluate their performance. As perceived, the temperature at the bulk and the membrane surface are compared with those reported in the literature [50]. The results calculated with the present model are within the deviation of $< \pm 2 \%$, showing the accuracy and reliability of the developed model.

Table 3. Bulk and membrane surface temperatures calculated at $\operatorname{Re}=100$ against the results reported in the literature [50].

\begin{tabular}{ccccccc}
\hline Section & \multicolumn{2}{c}{ Simulation Temperature (K) } & \multicolumn{2}{c}{ Ref. [50] } & \multicolumn{2}{c}{ Difference (\%) } \\
\hline- & Top Membrane & Top Bulk & Top Membrane & Top Bulk & Top Membrane & Top Bulk \\
\hline 0.05 & 346.4882 & 347.5521 & 342.467 & 348.136 & 1.174 & 0.167 \\
\hline 0.1 & 346.0447 & 347.20441 & 341.017 & 347.872 & 1.47 & 0.19 \\
\hline 0.15 & 345.6948 & 346.88848 & 339.831 & 346.817 & 1.72 & 0.02 \\
\hline
\end{tabular}

\section{Results and Discussion}

In Figure 4, the effect of the surface HTC, along with the membrane length at Reynolds numbers of 500 to 2000, is depicted. As can be seen, the maximum HTC is observed at the beginning length (entrance region) of the membrane. After the entrance region, the flow is fully developed, and HTC decreases gradually. Due to the thermal boundary layer (TBL) that forms at the entrance, all membrane angles showed the same HTC values at the entrance locations. However, it can be observed that, at low Reynolds numbers, the membrane angle has more influence on the rate of heat transfer and HTC. The higher the membrane angle, the more significant the heat transfer. At Reynolds number of 500 and for the position of $0.2 \mathrm{~m}$, by changing the membrane location from horizontal to vertical, the HTC is enhanced by $57 \%$. It is worth saying that the membrane angle efficacy diminishes by increasing the Reynolds number. 

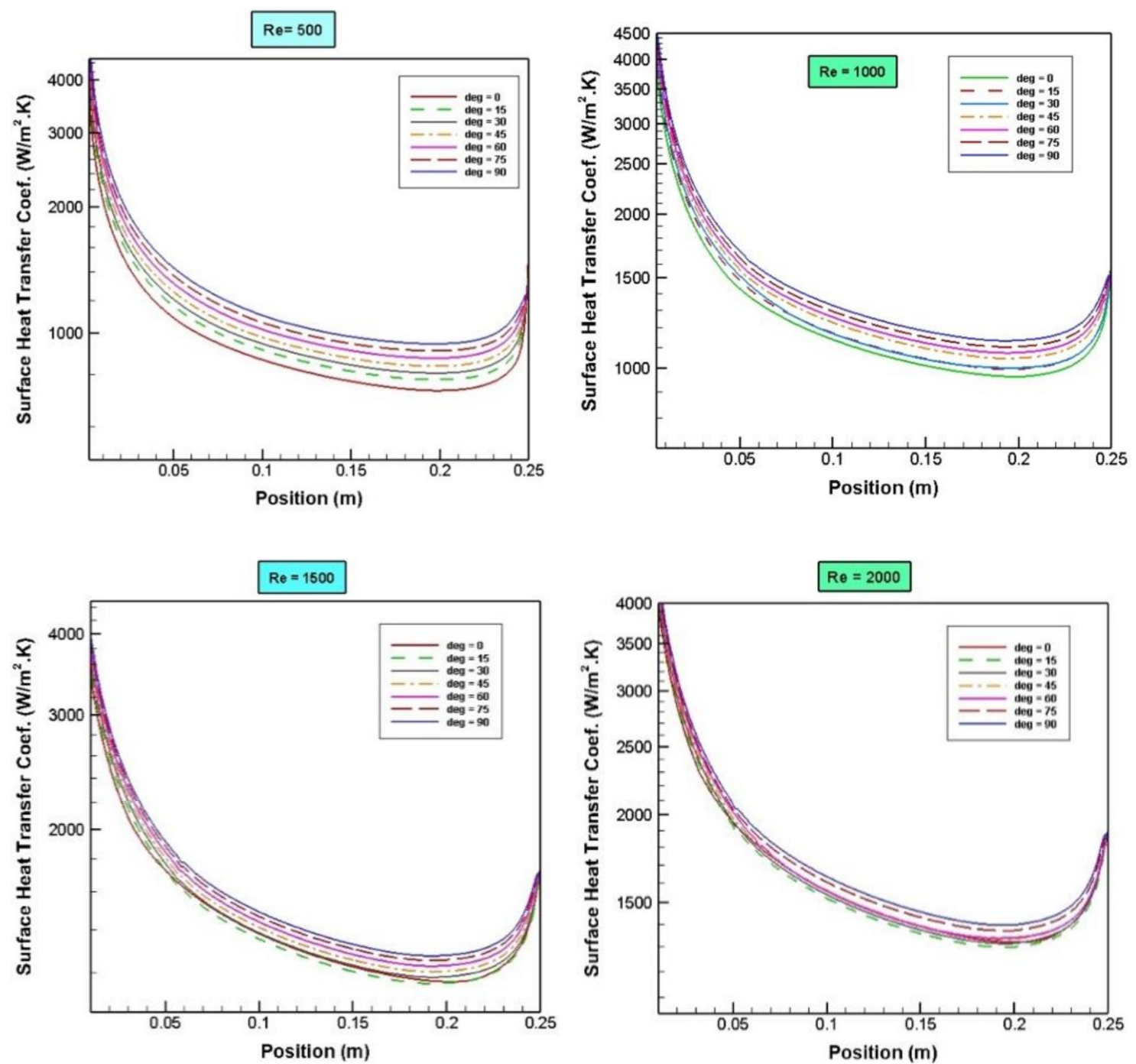

Figure 4. The variation of the surface HTC with the position at various Reynolds numbers.

Notably, the water vapor flux can potentially have a crucial role in DCMD performance. Some factors also affect the water vapor flux, where Reynolds number of the brine side is the most significant parameter identified in the literature [59]. For any particulate flows in microfluidics and conventional systems (e.g., systems with heat transfer), it has also been shown that Re number controls the performance and flow mapping of the systems [60-72].

Figure 5 shows the dependence of the surface HTC on the position at various Reynolds numbers. As can be seen, the increase in the Reynolds number up to 1500 can augment the HTC of all membrane angles, except for the inclination angle of $60^{\circ}$. At low Reynolds numbers, the TBL is thick, so the heat flux has a small value. An increase in the Reynolds number can result in a reduction in the thickness of the thermal boundary. Consequently, the heat flux value is augmented. The change in boundary layer thickness between 1500 and 1000 is smaller than the thickness change between 500 and 1000 . The change in the thickness and Reynolds number gradually diminishes until this trend stops, and a constant flat Reynolds number is reached. The argument behind this behavior is that, at low Reynolds number, due to the existence of a thick TBL, a weakly flux occurred. As the Reynolds number is enhanced, the TBL starts to be narrower. Now, it is expected that the flux will be significant until it attains a point that is not under the influence of the Reynolds number [73]. Notably, the HTC at the exit of the horizontal membrane (angle of $0^{\circ}$ ) enhances abruptly (see Figure 5a). In contrast, at the exit of the vertical membrane (angle of $90^{\circ}$ ), the HTC remains unchanged, with the same value before 
reaching the exit region (see Figure $5 \mathrm{~g}$ ). Thus, it can be concluded that by increasing the membrane angle from $0^{\circ}$ to $90^{\circ}$, the exit effects are reduced, and HTC is enhanced uniformly.

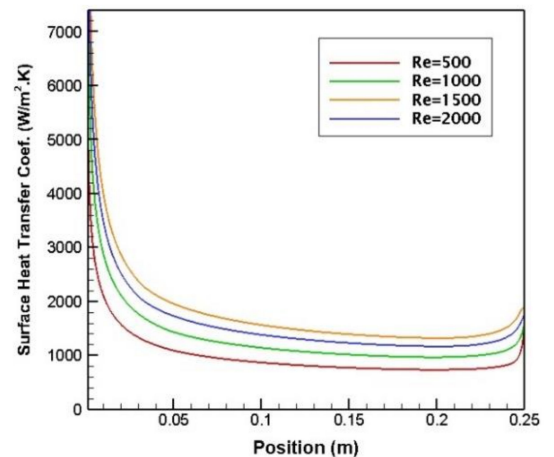

(a)

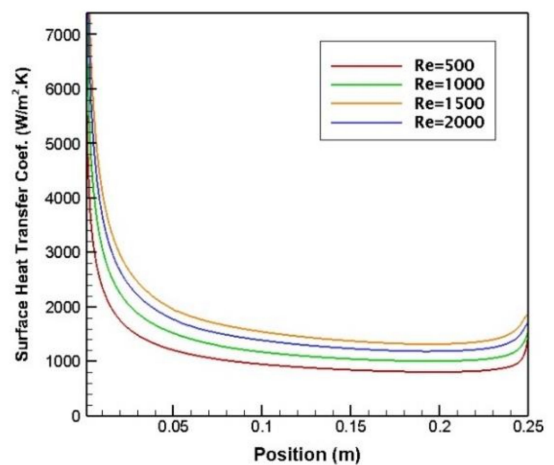

(c)

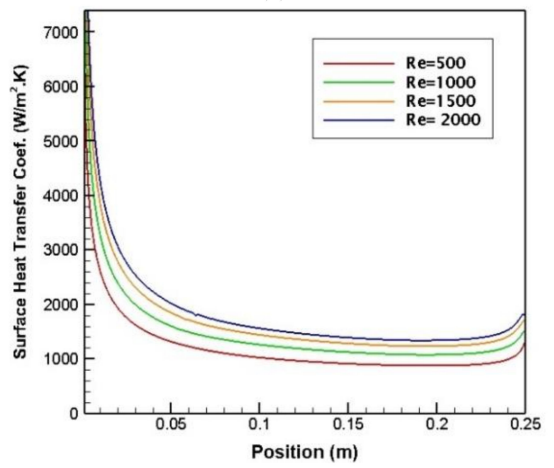

(e)

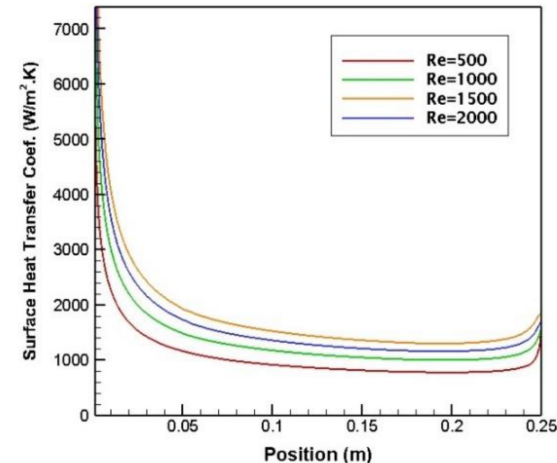

(b)

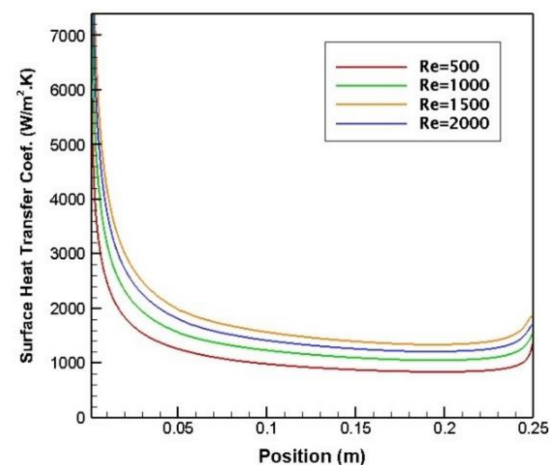

(d)

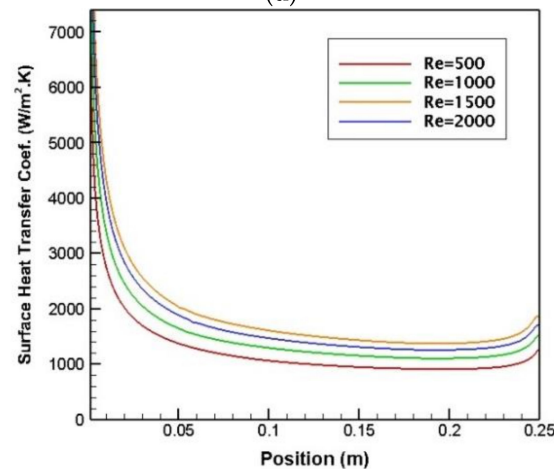

(f)

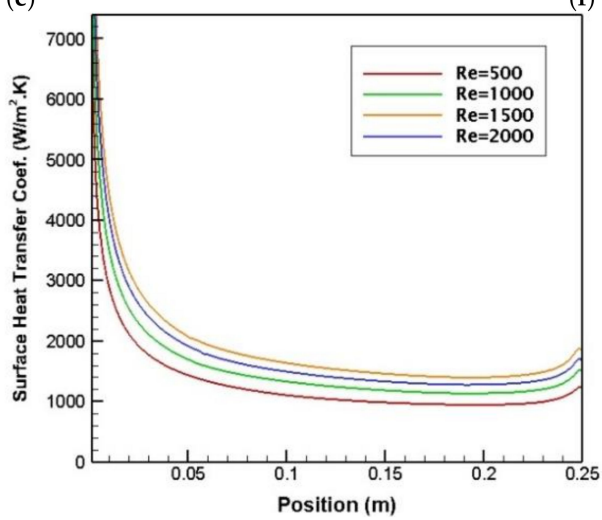

(g)

Figure 5. Variations of surface HTC in terms of the position at membrane angles of $(\mathbf{a}) 0^{\circ}$, (b) $15^{\circ}$, (c) $30^{\circ}$, (d) $45^{\circ}$, (e) $60^{\circ}$, (f) $75^{\circ}$ and (g) $90^{\circ}$. 
The temperature differences between the bulk flow of the permeate channel and its hot and cold walls for all range of membrane angles are represented in Figure $6 a, b$, respectively. It can be deduced that the increase in the Reynolds number will lead to a lower temperature difference for all angles and both hot and cold walls. At low Reynolds numbers, the differences between the values of $\Delta \mathrm{T}$ for various angles are considerable, whereas, by increasing the Reynolds number, the difference is suppressed until the temperatures are converged together. As can be seen in Figure $6 \mathrm{a}, \mathrm{b}$, the lowest temperature difference belongs to the membrane angle of $90^{\circ}$. This angle affects the temperature difference in the permeate channel at the cold wall more than the hot wall.

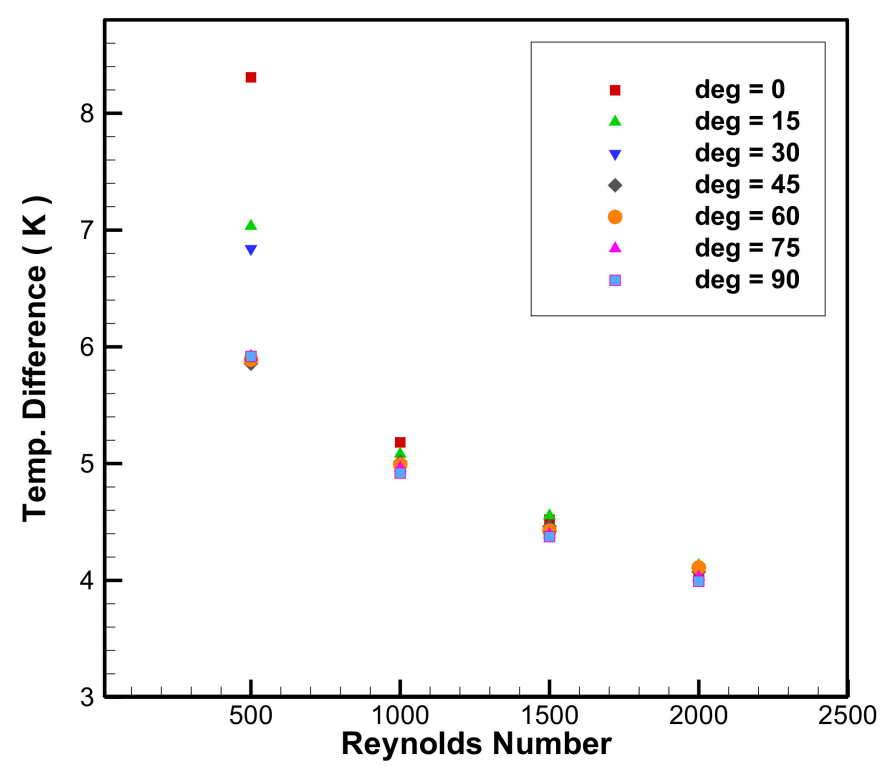

(a)

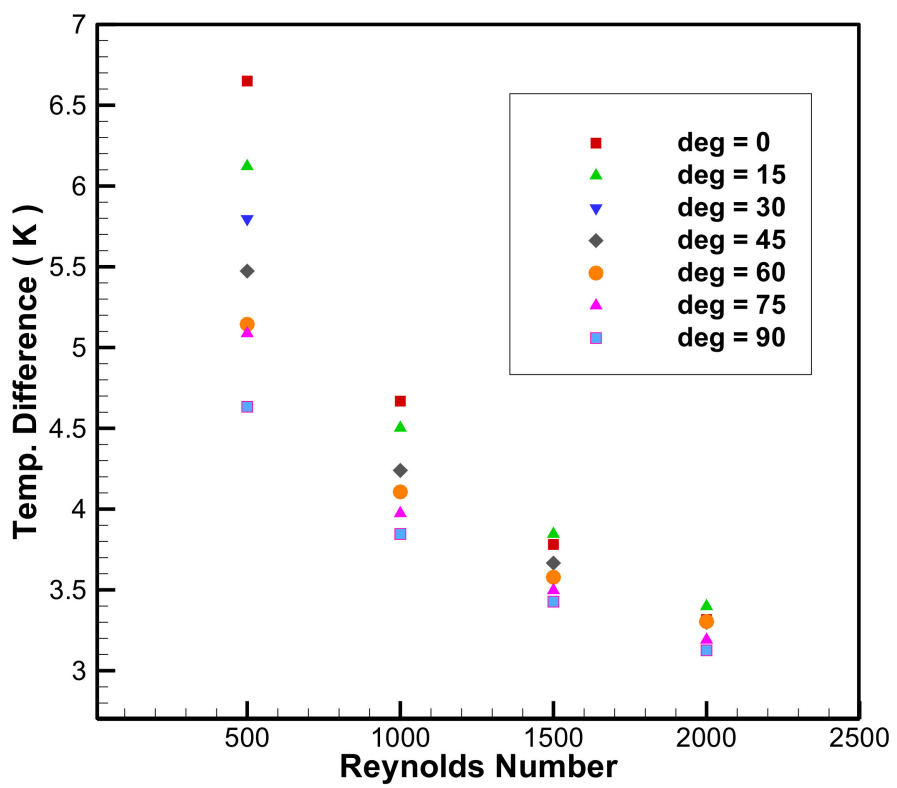

(b)

Figure 6. Temperature difference in the permeate channel at (a) the hot wall and (b) the cold wall.

In Figure 7, the temperature difference between the bulk flow of the feed channel and its hot and cold walls for a Reynolds number of 500 to 2000 are presented. It is worth saying that for Reynolds numbers between 1000 and 2000, the temperature difference value at the hot wall is constant, 
while, for the cold wall, the value of $\Delta \mathrm{T}$ decreases with a slight slope. For a Reynolds number of 500 (low flow velocity), the temperature difference value is diminished intensively. Notably, at this Reynolds number and at the $45^{\circ}<$ tilt angles $<90^{\circ}$, the temperature difference is constant for the hot wall, whereas it decreases sharply for the cold wall.

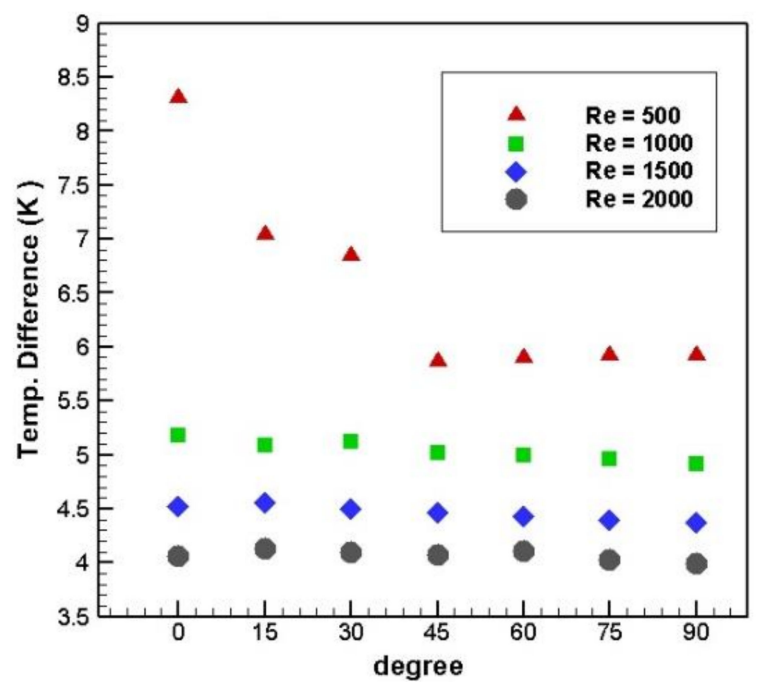

(a)

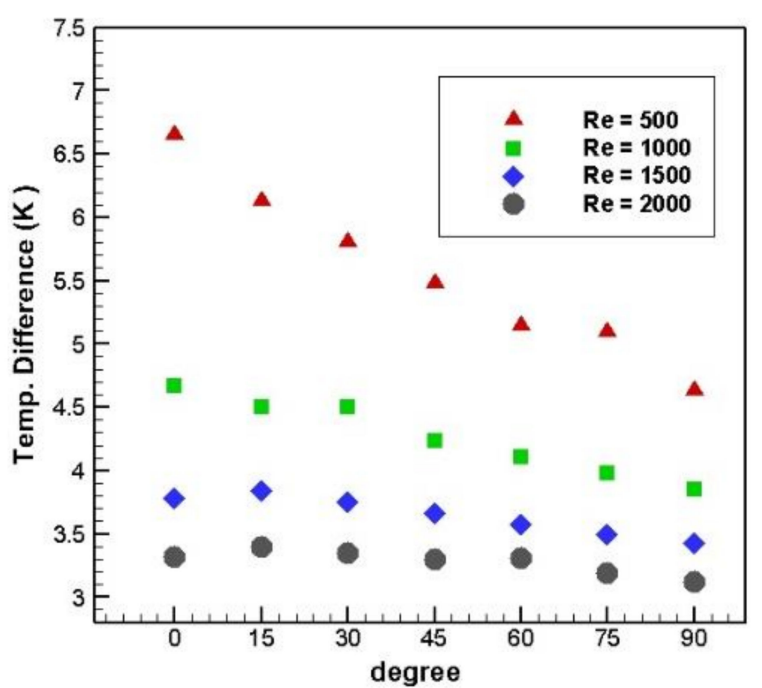

(b)

Figure 7. Temperature difference in feed channel at (a) hot wall and (b) cold wall.

Generally, increasing the Reynolds number means that potent fluid is flowing through the TBLs. Thus, the surface of the membrane will face more new fluids. Thus, the TBL considerably thinned. Consequently, the temperature difference between the membrane surface and the fluid bulk will be smaller. Accordingly, the potential of the driving force is more substantial. From Figures 6 and 7, it can be universally concluded that at high Reynolds number, the tilt angle has no significant effect on the temperature difference. However, at low Reynolds number, the tilt angle plays a remarkable role. At low Reynolds number, by increasing the tilt angle, the influence of convection flow due to the temperature difference between the exit and entrance of membrane will be apparent. So, at the vertical mode of configuration, the convection flow influence will be at the highest value. So, at tilt angle $90^{\circ}$ of Reynolds number of 500 , the temperature difference is the highest value (Thus, highest driving force), compared to other angles of this Reynolds number.

Figure 8 shows the contours of the temperature and the velocity distributions at the entire membrane system for the inclination angle of $0^{\circ}$ at a Reynolds number of 500. The maximum temperature variation in the permeate and feed channels occurred at the entrance, as well as with a marginal difference in the exit region. Hence, there is a high driving force available in these locations, which can be expected to improve the HTC at the entrance region. At the same time, it is small in the exit region, which follows the results already represented in Figures 4 and 5. As shown in Figure 8a, the velocity and TBLs in the feed channel are thicker than those calculated for the permeate channel. The temperature distribution in the membrane is the same as the mean temperature distribution in the boundary layer of permeate and feed channels as well. As also shown in Figure 8b, the velocity boundary layer has a parabolic behavior, meaning that the flow starts to be fully developed just after the entrance section. It is worth saying that the fluid flow strongly affects the rate of mass transfer determination. Hence, these findings can be tailored to the mass transfer phenomenon, which is beyond the goal of the present research. 


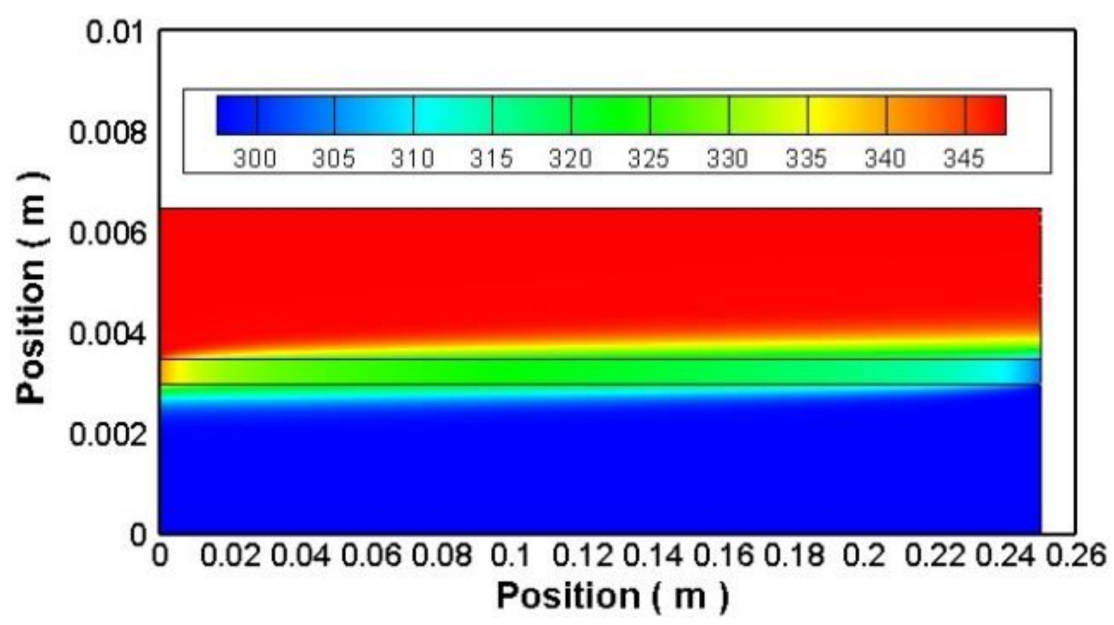

(a)

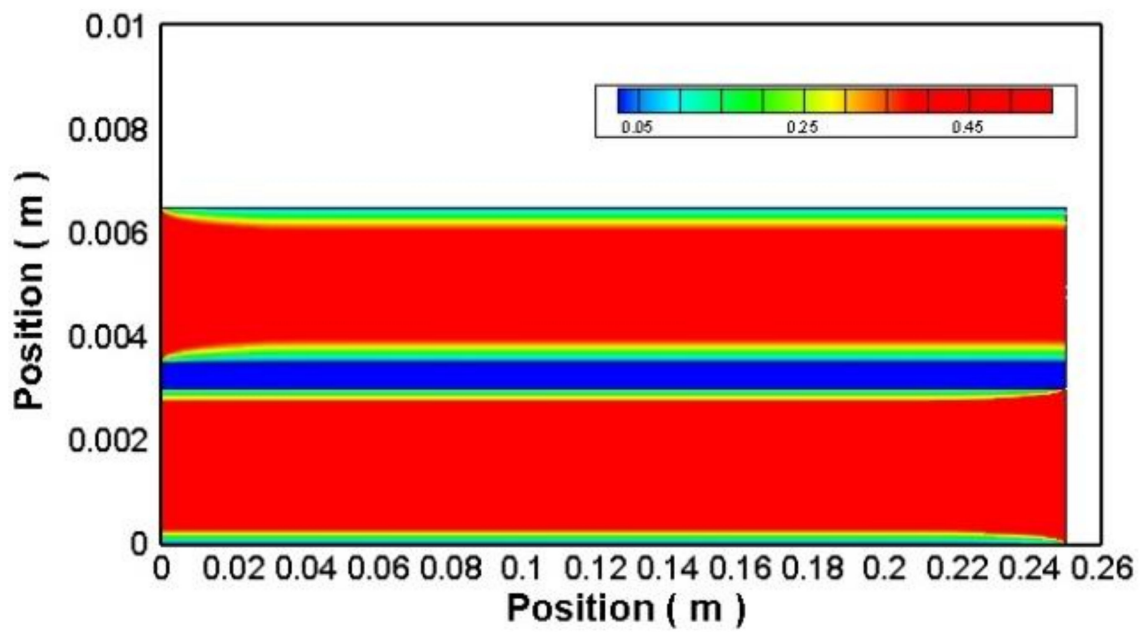

(b)

Figure 8. (a) Temperature and (b) velocity profile at the feed and permeate channels for the horizontal membrane obtained at Reynolds number of 500.

\section{Conclusions}

In the present investigation, a computational fluid dynamic (CFD) model was developed to assess a direct contact membrane distillation (DCMD) system considering the various membrane inclination angles and Reynolds numbers. A two-dimensional model was developed based on the Navier-Stokes, energy, and species transport equations as fluid flow and heat and mass transfer governing equations. The fluid flow was counter-current, and Reynolds number ranged between 500 and 2000. Modeling was conducted using 420,000 mesh elements optimized with a grid independency study. The results showed that for all membrane inclination angles, the optimum Reynolds number was 1500, except for the angle of $60^{\circ}$, in which the highest Reynolds number of 2000 was the optimum. Also, the effect of the exit region on the heat transfer was investigated, and it was identified that the exit region reduces the heat transfer rate by increasing the membrane angle up to $90^{\circ}$. The horizontal membrane with Reynolds number of 500 represented the most considerable temperature difference, and the vertical membrane with a Reynolds number of 2000 exhibited the lowest temperature difference.

Author Contributions: Conceptualization, A.A.A. and M.R.S.; methodology, A.A.A., Y.E. and M.G.; software, A.A.A. and M.R.S.; validation, A.A.A. and Y.E.; formal analysis, A.A.A. and Y.E.; investigation, A.A.A., Y.E., M.R.S. and M.G.; resources, A.A.A., M.G. and M.R.S.; data curation, A.A.A. and M.R.S.; writing-original draft preparation, A.A.A., Y.E., M.R.S. and M.G.; writing-review and editing, A.A.A. and M.G.; visualization, A.A.A. 
and Y.E.; supervision, A.A.A., M.G. and M.R.S.; project administration, A.A.A. and M.R.S.; funding acquisition, A.A.A. All authors have read and agreed to the published version of the manuscript.

Funding: This research was funded by the Public Authority for Applied Education (PAAET), grant number (TS-19-12).

Acknowledgments: The authors wish to express their sincere thanks to the Public Authority for Applied Education (PAAET) in Kuwait for funding this research, grant number (TS-19-12).

Conflicts of Interest: The authors of the present work declare no conflict of interest.

\section{References}

1. Alhathal Alanezi, A.; Sharif, A.O.; Sanduk, M.I.; Khan, A.R. Potential of membrane distillation-A comprehensive review. Int. J. Water 2013, 7, 317. [CrossRef]

2. Elhenawy, Y.; Elminshawy, N.A.; Bassyouni, M.; Alhathal Alanezi, A.; Drioli, E. Experimental and theoretical investigation of a new air gap membrane distillation module with a corrugated feed channel. J. Membr. Sci. 2020, 594, 117461. [CrossRef]

3. Alklaibi, A.; Lior, N. Membrane-distillation desalination: Status and potential. Desalination 2005, 171, 111-131. [CrossRef]

4. Elmarghany, M.R.; El-Shazly, A.H.; Salem, M.S.; Sabry, M.N.; Nady, N. Thermal analysis evaluation of direct contact membrane distillation system. Case Stud. Therm. Eng. 2019, 13, 100377. [CrossRef]

5. Shirazi, M.M.A.; Kargari, A.; Shirazi, M.J.A. Direct contact membrane distillation for seawater desalination. Desalination Water Treat. 2012, 49, 368-375. [CrossRef]

6. Alhathal Alanezi, A.; Sharif, A.O.; Sanduk, M.I.; Khan, A.R. Experimental Investigation of Heat and Mass Transfer in Tubular Membrane Distillation Module for Desalination. ISRN Chem. Eng. 2012, 2012, 1-8. [CrossRef]

7. Li, Q.; Beier, L.-J.; Tan, J.; Brown, C.; Lian, B.; Zhong, W.; Wang, Y.; Ji, C.; Dai, P.; Li, T.; et al. An integrated, solar-driven membrane distillation system for water purification and energy generation. Appl. Energy 2019, 237, 534-548. [CrossRef]

8. Abdallah, H.; Moustafa, A.; Alhathal Alanezi, A.; El-Sayed, H. Performance of a newly developed titanium oxide nanotubes/polyethersulfone blend membrane for water desalination using vacuum membrane distillation. Desalination 2014, 346, 30-36. [CrossRef]

9. Qtaishat, M.R.; Banat, F. Desalination by solar powered membrane distillation systems. Desalination 2013, 308, 186-197. [CrossRef]

10. Koschikowski, J.; Wieghaus, M.; Rommel, M.; Ortín, V.S.; Suarez, B.P.; Rodríguez, J.R.B. Experimental investigations on solar driven stand-alone membrane distillation systems for remote areas. Desalination 2009, 248, 125-131. [CrossRef]

11. Saffarini, R.B.; Summers, E.K.; Arafat, H.A. Technical evaluation of stand-alone solar powered membrane distillation systems. Desalination 2012, 286, 332-341. [CrossRef]

12. Camacho, L.M.; Dumée, L.F.; Zhang, J.; Li, J.-D.; Duke, M.; Gomez, J.; Gray, S. Advances in Membrane Distillation for Water Desalination and Purification Applications. Water 2013, 5, 94-196. [CrossRef]

13. Curcio, E.; Drioli, E. Membrane Distillation and Related Operations-A Review. Sep. Purif. Rev. 2005, 34, 35-86. [CrossRef]

14. Fane, A. (Tony) A grand challenge for membrane desalination: More water, less carbon. Desalination 2018, 426, 155-163. [CrossRef]

15. Alhathal Alanezi, A. Performance Enhancement of Air Bubbling and Vacuum Membrane Distillation for Water Desalination. Ph.D. Thesis, University of Surrey, Guildford, UK, 2013. Available online: https://ethos.bl.uk/OrderDetails.do?uin=uk.bl.ethos.576164 (accessed on 18 April 2013).

16. Fath, H.E.; Elsherbiny, S.M.; Hassan, A.A.; Rommel, M.; Wieghaus, M.; Koschikowski, J.; Vatansever, M. PV and thermally driven small-scale, stand-alone solar desalination systems with very low maintenance needs. Desalination 2008, 225, 58-69. [CrossRef]

17. Alsalhy, Q.F.; Ibrahim, S.S.; Khaleel, S.R. Performance of vacuum poly(propylene) membrane distillation (VMD) for saline water desalination. Chem. Eng. Process. Process. Intensif. 2017, 120, 68-80. [CrossRef] 
18. Jamed, M.J.; Alhathal Alanezi, A.; Alsalhy, Q.F. Effects of embedding functionalized multi-walled carbon nanotubes and alumina on the direct contact poly(vinylidene fluoride-co-hexafluoropropylene) membrane distillation performance. Chem. Eng. Commun. 2018, 206, 1035-1057. [CrossRef]

19. Schofield, R.; Fane, A.; Fell, C. Heat and mass transfer in membrane distillation. J. Membr. Sci. 1987, 33, 299-313. [CrossRef]

20. Alhathal Alanezi, A.; Abdallah, H.; El Zanati, E.; Ahmad, A.; Sharif, A.O. Performance Investigation of O-Ring Vacuum Membrane Distillation Module for Water Desalination. J. Chem. 2016, 2016, 1-11. [CrossRef]

21. Duong, H.; Chivas, A.; Nelemans, B.; Duke, M.; Gray, S.; Cath, T.Y.; Nghiem, L.D. Treatment of RO brine from CSG produced water by spiral-wound air gap membrane distillation-A pilot study. Desalination 2015, 366, 121-129. [CrossRef]

22. Wang, P.; Chung, T.-S.; Chung, T.-S. Recent advances in membrane distillation processes: Membrane development, configuration design and application exploring. J. Membr. Sci. 2015, 474, 39-56. [CrossRef]

23. Shirazi, M.M.A.; Kargari, A.; Ismail, A.F.; Matsuura, T. Computational Fluid Dynamic (CFD) opportunities applied to the membrane distillation process: State-of-the-art and perspectives. Desalination 2016, 377, 73-90. [CrossRef]

24. Summers, E.K.; Arafat, H.A.; Lienhard, J.H. Energy efficiency comparison of single-stage membrane distillation (MD) desalination cycles in different configurations. Desalination 2012, 290, 54-66. [CrossRef]

25. Alhathal Alanezi, A.; Sharif, A. Membrane Distillation: An Attractive Alternative. Arab Water World (AWW) 2012, 36, 16-18.

26. Ibrahim, S.S.; Alsalhy, Q.F. Modeling and simulation for direct contact membrane distillation in hollow fiber modules. AIChE J. 2012, 59, 589-603. [CrossRef]

27. Ramlow, H.; Machado, R.A.F.; Marangoni, C. Direct contact membrane distillation for textile wastewater treatment: A state of the art review. Water Sci. Technol. 2017, 76, 2565-2579. [CrossRef]

28. Mokhtar, N.; Lau, W.; Ismail, A.F.; Veerasamy, D. Membrane Distillation Technology for Treatment of Wastewater from Rubber Industry in Malaysia. Procedia CIRP 2015, 26, 792-796. [CrossRef]

29. Zakrzewska-Trznadel, G. Membrane processes in nuclear technology-application for liquid radioactive waste treatment. Sep. Purif. Technol. 2001, 22, 617-625. [CrossRef]

30. El-Abbassi, A.; Hafidi, A.; Khayet, M.; García-Payo, M.C. Integrated direct contact membrane distillation for olive mill wastewater treatment. Desalination 2013, 323, 31-38. [CrossRef]

31. Hausmann, A.; Sanciolo, P.; Vasiljevic, T.; Kulozik, U.; Duke, M. Performance assessment of membrane distillation for skim milk and whey processing. J. Dairy Sci. 2014, 97, 56-71. [CrossRef]

32. Hitsov, I.; Maere, T.; De Sitter, K.; Dotremont, C.; Nopens, I. Modelling approaches in membrane distillation: A critical review. Sep. Purif. Technol. 2015, 142, 48-64. [CrossRef]

33. Ali, A.; Macedonio, F.; Drioli, E.; Aljlil, S.; Alharbi, O. Experimental and theoretical evaluation of temperature polarization phenomenon in direct contact membrane distillation. Chem. Eng. Res. Des. 2013, 91, 1966-1977. [CrossRef]

34. Tamburini, G.A.; Micale, M.; Ciofalo, A. Cipollina, Experimental analysis via thermochromic liquid crystals of the temperature local distribution in membrane distillation modules. Chem. Eng. Trans. 2013, 32, 2041-2046.

35. Tamburini, A.; Pitò, P.; Cipollina, A.; Micale, G.; Ciofalo, M. A Thermochromic Liquid Crystals Image Analysis technique to investigate temperature polarization in spacer-filled channels for Membrane Distillation. J. Membr. Sci. 2013, 447, 260-273. [CrossRef]

36. Rezakazemi, M. CFD simulation of seawater purification using direct contact membrane desalination (DCMD) system. Desalination 2018, 443, 323-332. [CrossRef]

37. Shakaib, M.; Hasani, S.; Ahmed, I.; Yunus, R.M. A CFD study on the effect of spacer orientation on temperature polarization in membrane distillation modules. Desalination 2012, 284, 332-340. [CrossRef]

38. Al-Sharif, S.; Albeirutty, M.; Cipollina, A.; Micale, G. Modelling flow and heat transfer in spacer-filled membrane distillation channels using open source CFD code. Desalination 2013, 311, 103-112. [CrossRef]

39. Mabrouk, A.N.; Elhenawy, Y.; Abdelkader, M.; Shatat, M. The impact of baffle orientation on the performance of the hollow fiber membrane distillation. Desalin. Water Treat. 2017, 58, 35-45. [CrossRef]

40. Bui, V.A.; Vu, L.; Nguyen, M.H. Modelling the simultaneous heat and mass transfer of direct contact membrane distillation in hollow fibre modules. J. Membr. Sci. 2010, 353, 85-93. [CrossRef]

41. Janajreh, I.; Suwwan, D. Numerical simulation of Direct Contact Membrane Desalination in conjugate heat transfer configuration: Role of Membrane Conductivity. Sustain. Water Environ. Syst. 2014, 6, 81-87. 
42. Tang, N.; Zhang, H.; Wang, W. Computational fluid dynamics numerical simulation of vacuum membrane distillation for aqueous $\mathrm{NaCl}$ solution. Desalination 2011, 274, 120-129. [CrossRef]

43. Awad, M.; Janajreh, I.; Fath, H.; Awad, M. Low Energy Direct Contact Membrane Distillation: Towards optimal flow configuration. In Proceedings of the 2013 International Renewable and Sustainable Energy Conference (IRSEC), Ouarzazate, Morocco, 7-9 March 2013; pp. 471-476.

44. Janajreh, I.; El Kadi, K.; Al Hammadie, N.; Hashaikeh, R. Direct contact membrane distillation: The role of membrane porosity. Desalination Water Treat. 2017, 100, 258-267. [CrossRef]

45. Chen, T.-C.; Ho, C.-D.; Yeh, H.-M. Theoretical modeling and experimental analysis of direct contact membrane distillation. J. Membr. Sci. 2009, 330, 279-287. [CrossRef]

46. Bahmanyar, A.; Asghari, M.; Khoobi, N. Numerical simulation and theoretical study on simultaneously effects of operating parameters in direct contact membrane distillation. Chem. Eng. Process. Process. Intensif. 2012, 61, 42-50. [CrossRef]

47. Janajreh, I.; Hussain, M.N.; Hashaikeh, R.; Ahmed, R. Thermal efficiency enhancement of the direct contact membrane distillation: Conductive layer integration and geometrical undulation. Appl. Energy 2018, 227, 7-17. [CrossRef]

48. Gopi, G.; Arthanareeswaran, G.; Ismail, A.F. Perspective of renewable desalination by using membrane distillation. Chem. Eng. Res. Des. 2019, 144, 520-537. [CrossRef]

49. Khayet, M.; Matsuura, T. Membrane Distillation: Principles and Applications; Elsevier: Amsterdam, The Netherlands, 2011.

50. Janajreh, I.; El Kadi, K.; Hashaikeh, R.; Ahmed, R. Numerical investigation of air gap membrane distillation (AGMD): Seeking optimal performance. Desalination 2017, 424, 122-130. [CrossRef]

51. Ho, C.-D.; Chang, H.; Chang, C.-L.; Huang, C.-H. Theoretical and experimental studies of flux enhancement with roughened surface in direct contact membrane distillation desalination. J. Membr. Sci. 2013, 433, 160-166. [CrossRef]

52. Karimipour, A. A novel case study for thermal radiation through a nanofluid as a semitransparent medium via discrete ordinates method to consider the absorption and scattering of nanoparticles along the radiation beams coupled with natural convection. Int. Commun. Heat Mass Transf. 2017, 87, 256-269. [CrossRef]

53. Janajreh, I.; Suwwan, D.; Hashaikeh, R. Theoretical and experimental study of direct contact membrane distillation. Desalination Water Treat. 2015, 57, 15660-15675. [CrossRef]

54. Goodarzi, M.; Safaei, M.R.; Vafai, K.; Ahmadi, G.; Dahari, M.; Kazi, S.; Jomhari, N. Investigation of nanofluid mixed convection in a shallow cavity using a two-phase mixture model. Int. J. Therm. Sci. 2014, 75, 204-220. [CrossRef]

55. Safaei, M.R.; Togun, H.; Vafai, K.; Kazi, S.N.; Badarudin, A. Investigation of Heat Transfer Enhancement in a Forward-Facing Contracting Channel Using FMWCNT Nanofluids. Numer. Heat Transfer Part A Appl. 2014, 66, 1321-1340. [CrossRef]

56. Gheynani, A.R.; Akbari, O.A.; Zarringhalam, M.; Shabani, G.A.S.; A Alnaqi, A.; Goodarzi, M.; Toghraie, D. Investigating the effect of nanoparticles diameter on turbulent flow and heat transfer properties of non-Newtonian carboxymethyl cellulose/CuO fluid in a microtube. Int. J. Numer. Methods Heat Fluid Flow 2019, 29, 1699-1723. [CrossRef]

57. Amiri, M.H.; Keshavarzi, A.; Karimipour, A.; Bahiraei, M.; Goodarzi, M.; Esfahani, J.A. A 3-D numerical simulation of non-Newtonian blood flow through femoral artery bifurcation with a moderate arteriosclerosis: Investigating Newtonian/non-Newtonian flow and its effects on elastic vessel walls. Heat Mass Transf. 2019, 55, 2037-2047. [CrossRef]

58. Goodarzi, M.; Javid, S.; Sajadifar, A.; Nojoomizadeh, M.; Motaharipour, S.H.; Bach, Q.-V.; Karimipour, A. Slip velocity and temperature jump of a non-Newtonian nanofluid, aqueous solution of carboxy-methyl cellulose/aluminum oxide nanoparticles, through a microtube. Int. J. Numer. Methods Heat Fluid Flow 2019, 29, 1606-1628. [CrossRef]

59. Singh, D.; Sirkar, K.K. Performance of PVDF flat membranes and hollow fibers in desalination by direct contact membrane distillation at high temperatures. Sep. Purif. Technol. 2017, 187, 264-273. [CrossRef]

60. Kamalgharibi, M.; Hormozi, F.; Zamzamian, S.A.; Sarafraz, M.M. Experimental studies on the stability of $\mathrm{CuO}$ nanoparticles dispersed in different base fluids: Influence of stirring, sonication and surface active agents. Heat Mass Transf. 2015, 52, 55-62. [CrossRef] 
61. Nakhjavani, M.; Nikkhah, V.; Shoja, S.; Sarafraz, M.M.; Sarafraz, M. Green synthesis of silver nanoparticles using green tea leaves: Experimental study on the morphological, rheological and antibacterial behaviour. Heat Mass Transf. 2017, 53, 3201-3209. [CrossRef]

62. Salari, E.; Peyghambarzadeh, S.; Sarafraz, M.M.; Hormozi, F.; Nikkhah, V. Thermal behavior of aqueous iron oxide nano-fluid as a coolant on a flat disc heater under the pool boiling condition. Heat Mass Transf. 2016, 53, 265-275. [CrossRef]

63. Sarafraz, M.M. Experimental Investigation on Pool Boiling Heat Transfer to Formic Acid, Propanol and 2-Butanol Pure Liquids under the Atmospheric Pressure. J. Appl. Fluids 2013, 6, 73-79.

64. Sarafraz, M.M.; Arjomandi, M. Thermal performance analysis of a microchannel heat sink cooling with copper oxide-indium (CuO/In) nano-suspensions at high-temperatures. Appl. Therm. Eng. 2018, 137, 700-709. [CrossRef]

65. Sarafraz, M.M.; Arya, A.; Hormozi, F.; Nikkhah, V. On the convective thermal performance of a CPU cooler working with liquid gallium and $\mathrm{CuO} /$ water nanofluid: A comparative study. Appl. Therm. Eng. 2017, 112, 1373-1381. [CrossRef]

66. Sarafraz, M.M. Thermal Performance and Viscosity of Biologically Produced Silver/Coconut Oil Nanofluids. Chem. Biochem. Eng. Q. 2017, 30, 489-500. [CrossRef]

67. Sarafraz, M.M.; Hormozi, F. Intensification of forced convection heat transfer using biological nanofluid in a double-pipe heat exchanger. Exp. Therm. Fluid Sci. 2015, 66, 279-289. [CrossRef]

68. Sarafraz, M.M.; Hormozi, F.; Kamalgharibi, M. Sedimentation and convective boiling heat transfer of CuO-water/ethylene glycol nanofluids. Heat Mass Transf. 2014, 50, 1237-1249. [CrossRef]

69. Sarafraz, M.M.; Hormozi, F.; Peyghambarzadeh, S. Role of nanofluid fouling on thermal performance of a thermosyphon: Are nanofluids reliable working fluid? Appl. Therm. Eng. 2015, 82, 212-224. [CrossRef]

70. Alhathal Alanezi, A.; Altaee, A.; Sharif, A.O. The effect of energy recovery device and feed flow rate on the energy efficiency of reverse osmosis process. Chem. Eng. Res. Des. 2020, 158, 12-23. [CrossRef]

71. Sarafraz, M.M.; Nikkhah, V.; Nakhjavani, M.; Arya, A. Thermal performance of a heat sink microchannel working with biologically produced silver-water nanofluid: Experimental assessment. Exp. Therm. Fluid Sci. 2018, 91, 509-519. [CrossRef]

72. Sarafraz, M.M.; Hormozi, F. Convective boiling and particulate fouling of stabilized CuO-ethylene glycol nanofluids inside the annular heat exchanger. Int. Commun. Heat Mass Transf. 2014, 53, 116-123. [CrossRef]

73. Manawi, Y.; Khraisheh, M.; Fard, A.K.; Benyahia, F.; Adham, S. Effect of operational parameters on distillate flux in direct contact membrane distillation (DCMD): Comparison between experimental and model predicted performance. Desalination 2014, 336, 110-120. [CrossRef] 